\title{
Generation of the lower-thermospheric vertical wind estimated with the EISCAT KST radar at high latitudes during periods of moderate geomagnetic disturbance
}

\author{
S. Oyama ${ }^{1,2}$, B. J. Watkins ${ }^{2}$, S. Maeda ${ }^{3}$, H. Shinagawa ${ }^{4}$, S. Nozawa ${ }^{1}$, Y. Ogawa ${ }^{5}$, A. Brekke ${ }^{6}$, C. Lathuillere $^{7}$, and \\ W. Kofman ${ }^{7}$ \\ ${ }^{1}$ Solar-Terrestrial Environment Laboratory, Nagoya University, Nagoya, Japan \\ ${ }^{2}$ Geophysical Institute, University of Alaska Fairbanks, Fairbanks, AK, USA \\ ${ }^{3}$ Kyoto Women's University, Kyoto, Japan \\ ${ }^{4}$ National Institute of Information and Communications Technology, Koganei, Japan \\ ${ }^{5}$ National Institute of Polar Research, Tokyo, Japan \\ ${ }^{6}$ Faculty of Science, University of Troms $\varnothing$, Troms $\varnothing$, Norway \\ ${ }^{7}$ Laboratoire de Planetologie de Grenoble, Batiment D de Physique, Grenoble, France
}

Received: 20 April 2007 - Revised: 4 April 2008 - Accepted: 29 April 2008 - Published: 11 June 2008

\begin{abstract}
Lower-thermospheric winds at high latitudes during moderately-disturbed geomagnetic conditions were studied using data obtained with the European Incoherent Scatter (EISCAT) Kiruna-Sodankylä-Troms $\varnothing$ (KST) ultrahigh frequency (UHF) radar system on 9-10 September 2004. The antenna-beam configuration was newly designed to minimize the estimated measurement error of the vertical neutralwind speed in the lower thermosphere. This method was also available to estimate the meridional and zonal components. The vertical neutral-wind speed at $109 \mathrm{~km}, 114 \mathrm{~km}$, and $120 \mathrm{~km}$ heights showed large upward motions in excess of $30 \mathrm{~m} \mathrm{~s}^{-1}$ in association with an ionospheric heating event. Large downward speeds in excess of $-30 \mathrm{~m} \mathrm{~s}^{-1}$ were also observed before and after the heating event. The meridional neutral-wind speed suddenly changed its direction from equatorward to poleward when the heating event began, and then returned equatorward coinciding with a decrease in the heating event. The magnetometer data from northern Scandinavia suggested that the center of the heated region was located about $80 \mathrm{~km}$ equatorward of Troms $\varnothing$. The pressure gradient caused the lower-thermospheric wind to accelerate obliquely upward over Troms $\varnothing$ in the poleward direction. Acceleration of the neutral wind flowing on a vertically tilted isobar produced vertical wind speeds larger by more than two orders of magnitude than previously predicted, but still an order of magnitude smaller than observed speeds.
\end{abstract}

Correspondence to: S. Oyama

(soyama@ stelab.nagoya-u.ac.jp)
Keywords. Ionosphere (Ionosphere-atmosphere interactions; Polar ionosphere) - Meteorology and atmospheric dynamics (Thermospheric dynamics)

\section{Introduction}

To a reasonable initial approximation, the atmosphere is balanced in equilibrium between gravity and the vertical pressure gradient. Vertical displacement of an air parcel tends to be compensated by the pressure, temporarily destroying the balance with gravity; then, if no other force comes into play, the air parcel seeks to return to equilibrium by oscillating at a certain unique frequency. This frequency is known as the Brunt-Väisälä or buoyancy frequency, which is a function of the temperature of neutral particles (referred to as the neutral temperature). The neutral temperature may be estimated from the spectrum analysis of the vertical wind data, if vertical oscillations at the Brunt-Väisälä frequency are obvious in the data (Revathy et al., 1996; Mohan et al., 2001). However, according to previous observations with the Fabry-Perot interferometer (FPI) (Peteherych et al., 1985; Price and Jacka, 1991; Price et al., 1995; Smith and Hernandez, 1995; Ishii et al., 1999, 2001, 2004), external forces associated with geomagnetic activity may vertically accelerate the air parcel in the lower thermosphere at high latitudes. These observations suggest that dissipation of the Joule and particle-heating energies in the lower thermosphere is relevant to generation of

Published by Copernicus Publications on behalf of the European Geosciences Union. 
the notable vertical motions; however, the question of how these energies are dissipated in the polar ionosphere/lower thermosphere and transformed into thermospheric motions has not yet been elucidated (Fujii et al., 1998, 1999; Thayer, 1998, 2000). The processes must be height-dependent because there is altitudinal variability in the collisions between ionized and neutral particles in the thermosphere-ionosphere coupled system.

The objective of this paper is to report the characteristics of three components (meridional, zonal, and vertical) of the lower-thermospheric wind velocity estimated with the European Incoherent Scatter (EISCAT) radar, especially for periods of moderate geomagnetic disturbance. While this paper will present events of large vertical wind speeds in excess of $30 \mathrm{~m} \mathrm{~s}^{-1}$ in the lower thermosphere, note that such large vertical winds are unusual phenomena even at high latitudes. Statistical analysis of the vertical ion speed measured with the EISCAT radar at Troms $\varnothing$ reveals almost zero speed on average, although short-term fluctuations may have significant amplitudes in excess of $20 \mathrm{~m} \mathrm{~s}^{-1}$ (Oyama et al., 2005a). While many researchers have studied vertical wind speeds in the mesosphere and the lower atmosphere (Woodman and Guillen, 1974; Rastogi and Bowhill, 1976; Kofman et al., 1984; Larsen et al., 1987; Fritts et al., 1990; Fukao et al., 1991; Fritts and Hoppe, 1995; Hoppe and Fritts, 1995; Mitchell and Howells, 1998; Zhou, 2000; Caccia et al., 2004), the vertical-speed variance at $80-90 \mathrm{~km}$ heights is in general less than $10 \mathrm{~m}^{2} \mathrm{~s}^{-2}$ independent of season and observation location (Fritts and Yuan, 1989; Fritts et al., 1990; Nastrom et al., 1990; Wang and Fritts, 1990; Fritts and Hoppe, 1995; Tao and Gardner, 1995; Mitchell and Howells, 1998).

Section 2 describes the data set from the incoherent scatter (IS) radar and the methodology used to estimate the neutralwind velocity using these data. Observation results from the EISCAT Kiruna-Sodankylä-Troms $\varnothing$ (KST) ultrahigh frequency (UHF) radar system (Troms $\emptyset$ radar site: $69.6^{\circ} \mathrm{N}$, $19.2^{\circ} \mathrm{E}, 66.6^{\circ}$ magnetic latitude; $\mathrm{UT}=\mathrm{LT}-1 \mathrm{~h}$ ) are described in Sect. 3. The physical process causing temporal variations in the lower-thermospheric wind during a moderatelydisturbed period is discussed in Sect. 4. Section 5 summarizes the observation results and discussion, and presents conclusions.

\section{EISCAT radar measurement}

The tristatic experiment with the EISCAT KST UHF radar system was conducted from 03:01 UT on 9 September to 11:22 UT on 10 September 2004. The transmitter was located at the Troms $\varnothing$ site, and the receivers at all three sites. The Tromsø UHF radar antenna was directed to the geographic zenith. An advantage of this antenna configuration is to directly provide the vertical ion speed, which is an important parameter for calculating the vertical component of the neutral wind. In the case of the traditional EISCAT KST CP-1 (Common Program 1) method, which also adopts the tristatic approach, the vertical ion speed needs vectorial calculations using three line-of-sight ion speeds from the KST radars because the Troms $\varnothing$ antenna direction for the CP-1 method is along the magnetic field line. The vectorial calculations introduce additional errors into the vertical neutralwind speed. The new system reduces the estimated errors by $38.6 \%, 47.4 \%, 50.9 \%$, and $47.0 \%$ of the CP-1 method at $106,109,114$, and $120 \mathrm{~km}$, respectively, on average during the experiment. The estimated errors shown in the figures are derived with the error propagation analyses using the measurement uncertainty of the radar data.

The tristatic measurement was carried out at four $E$-region heights $(106,109,114$, and $120 \mathrm{~km})$ and at $282 \mathrm{~km}$ above Troms $\varnothing$ by pointing the Kiruna and Sodankylä radar antennae to the common volume at each height. The tristatic measurement sequence was $106,109,282,114,120$, and $282 \mathrm{~km}$, then a return to $106 \mathrm{~km}$; the duration of one sequence was $8 \mathrm{~min}$. The electric field was derived from the ion velocity at $282 \mathrm{~km}$, where ions and electrons are assumed collisionless and follow $\boldsymbol{E} \times \boldsymbol{B}$ drift motions. The integration time of the remote site data at each height was about $1 \mathrm{~min}$. The $K_{p}$ index was $1+$ or smaller during the experiment except for 21:00-24:00 UT on 9 September $2004\left(K_{p}=2\right)$. The daily $10.7-\mathrm{cm}$ solar radio flux (F10.7) was 132.8 and 131.8 $\left(10^{-22} \mathrm{~W} \mathrm{~m}^{-2} \mathrm{~Hz}^{-1}\right)$ on 9 and 10 September 2004, respectively. For the moderately-disturbed period, the radar observed large magnitudes of the electric field in excess of $50 \mathrm{mV} \mathrm{m}^{-1}$; the focus of this paper is on wind dynamics in the lower thermosphere for this period.

The neutral-wind velocity is derived from the steadystate ion-momentum equation neglecting ambipolar diffusion (Rino et al., 1977; Nozawa and Brekke, 1995, 1999; Oyama et al., 2005b):

$\boldsymbol{U}=\boldsymbol{V}-\frac{\Omega_{i}}{B v_{i n}}(\boldsymbol{E}+\boldsymbol{V} \times \boldsymbol{B})$

where $\boldsymbol{U}, \boldsymbol{V}, \boldsymbol{B}$, and $\boldsymbol{E}$ are vectors of the neutral-wind velocity, the ion velocity, the magnetic field, and the electric field, respectively, $\boldsymbol{B}$ is magnitude of the magnetic field, $\Omega_{i}$ is the ion gyrofrequency, and $v_{\text {in }}$ is the ion-neutral collision frequency, which is calculated using the equation by Brekke and Hall (1988). The assumption of neglecting the ambipolar diffusion is acceptable at $E$-region heights because the ion-diffusion speed along the magnetic field line is considerably smaller than the observed field-aligned ion speed for heights below about $230 \mathrm{~km}$ (Oyama et al., 2003). The thermospheric density is calculated using the Mass Spectrometer Incoherent Scatter (MSIS) model (Hedin, 1991).

\section{Observation results}

Figure 1 shows temporal variations in the electric field (top panel; northward and eastward are blue and red, 

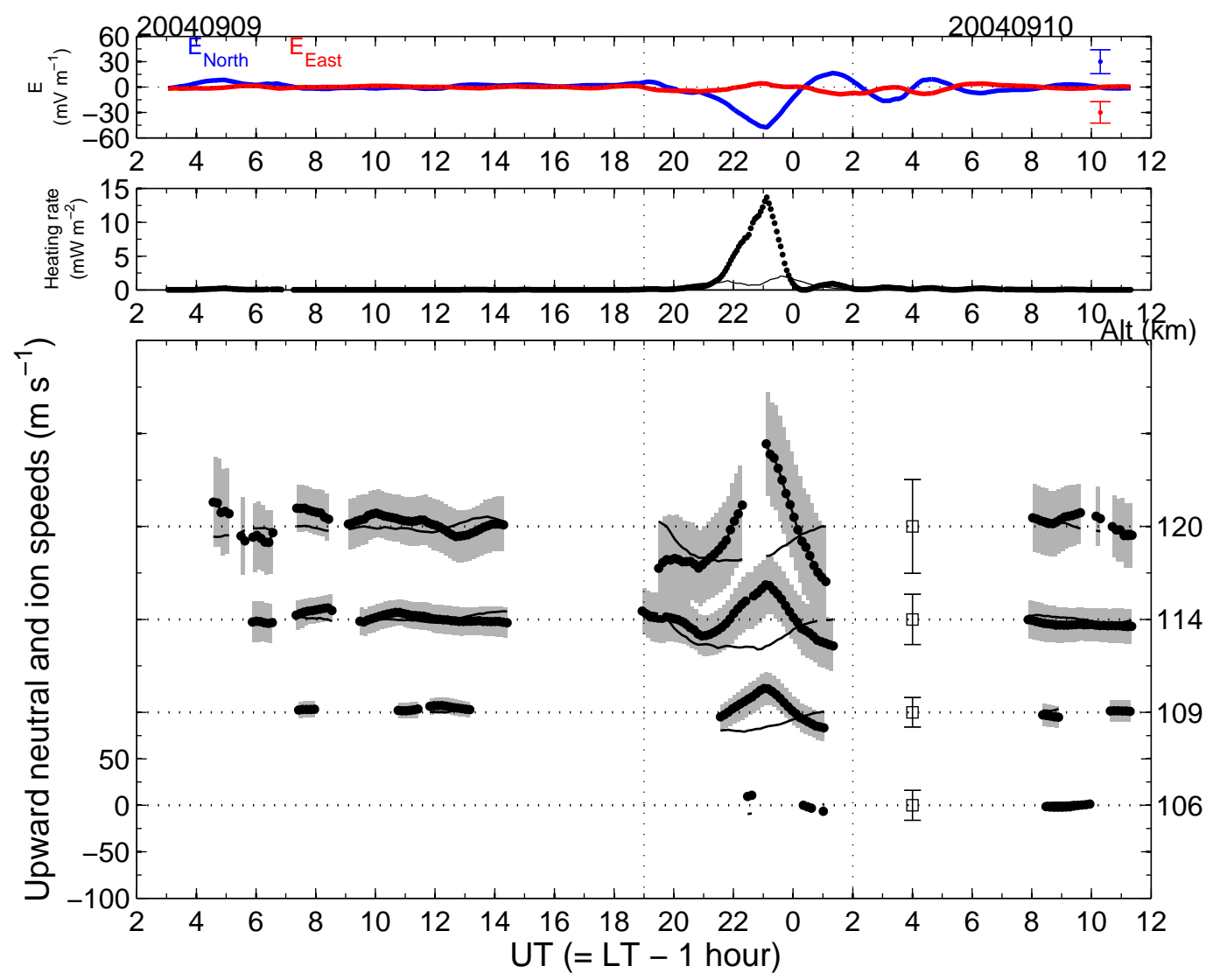

Fig. 1. Upper panel shows temporal variations in northward (blue) and eastward (red) components of the electric field measured with the EISCAT KST UHF radar from 03:00 UT on 9 September to 11:00 UT on 10 September 2004. Vertical bars at the right-hand-side are the mean error values from 19:00 to 02:00 UT with $\pm 1 \sigma$ for each component. Middle panel shows the height-integrated passive-energy deposition rate, $\Sigma_{p} E^{2}$ (dotted line), and the height-integrated particle heating rate (solid line) from 19:00 to 02:00 UT. Bottom panel shows the upward neutral-wind speed (solid curve with dots) and the upward ion speed (solid curve) from 106 to $120 \mathrm{~km}$. The estimated error of vertical neutral-wind speed is shown by gray shading above and below the line. The vertical bar with a square at each height is the mean error value $\pm 1 \sigma$ of the vertical neutral-wind speed from 19:00 to 02:00 UT. Horizontal dotted lines illustrate $0 \mathrm{~m} \mathrm{~s}^{-1}$ at each height. Vertical dotted lines in each panel are plotted at 19:00 UT on 9 September and 02:00 UT on 10 September 2004. All values are calculated using running-averaged data with 64-min boxcar window length.

respectively), the height-integrated passive-energy deposition rate (dotted line in the middle panel; Brekke and Rino, 1978; Fujii et al., 1998, 1999; Thayer, 2000), the heightintegrated particle heating rate (solid line in the middle panel; Vickrey et al., 1982), and the vertical ion and neutral-wind speeds (solid line and solid line with dots, respectively, in the bottom panel) at 106, 109, 114, and $120 \mathrm{~km}$ from 03:00 UT on 9 September to 11:00 UT on 10 September 2004. The estimated error of the vertical neutral-wind speed is shown by gray shading above and below the line, and the mean error from 19:00 to 02:00 UT at each height is illustrated by vertical bars with squares. The method of deriving the heating rates will be mentioned in Appendix A. Since data measured with the Kiruna and Sodankylä radars at $E$-region heights were sparse due to low signal-to-noise ratio (SNR; not shown here), we apply a running-average method to the data (detailed explanation in Appendix B.). This method is also applied to data from the Troms $\emptyset$ radar. To make the figure, a 64-min boxcar window length, which corresponds to 8 data points, is selected to smooth data of the ion velocity, electron density, and ion and electron temperatures. Some smoothed data are rejected for periods of sparse data. The neutral-wind velocity calculated using data smoothed with various boxcar window lengths is shown in Appendix B as a reference for readers. Since the objective of this paper is to present characteristics of the lower-thermospheric wind for the moderately-disturbed period, discussion is concentrated on the period from 19:00 UT on 9 September to 02:00 UT on 10 September. Mean error values of the electric field and the vertical neutral-wind speed from 19:00 to 02:00 UT are also presented in each panel. In general the measurement uncertainty during geomagnetically quiet periods is smaller than 
that during disturbed periods, and the mean error values during disturbed periods are larger than averages over the entire experimental period by about $20 \%$.

The height-integrated passive-energy deposition rate ( $\Sigma_{p} E^{2}$ where $\Sigma_{p}$ is the height-integrated Pedersen conductivity or the Pedersen conductance, and $E$ is the electricfield magnitude) has a maximum value of $14 \mathrm{~mW} \mathrm{~m}^{-2}$ when the electric field has a maximum value of $58 \mathrm{mV} \mathrm{m}^{-1}$ at 23:00 UT. After 02:00 UT, $\Sigma_{p} E^{2}$ does not show notable enhancements, although the electric field magnitude exhibits several small peaks from 02:00 to 06:00 UT. Since the Pedersen conductivity always peaks near $120 \mathrm{~km}$ altitude over the Troms $\varnothing$ site (Schlegel, 1988), the passive-energy deposition rate also peaks at that altitude. However, this does not suggest that $120 \mathrm{~km}$ is the most effective height level at which energy is transferred to neutral particles. In this paper we use $\Sigma_{p} E^{2}$ to identify the heating event, and do not evaluate height profiles of the passive-energy deposition rate. The height profile of the energy deposition rate is an important issue to address for achieving complete understanding of the lower-thermospheric wind dynamics, and it may be studied in future by calculating the Joule heating rate including effects of the neutral-wind velocity.

The height-integrated particle heating rate exhibits peaks at 22:00 and 00:00 UT. Horizontal patterns of the $D$-region absorption measured at Kilpisjärvi, Finland $\left(69.05^{\circ} \mathrm{N}\right.$, $20.79^{\circ} \mathrm{E}$; about $80 \mathrm{~km}$ southeast from Troms $\varnothing$ ) at these times were checked to identify the location of Troms $\varnothing$ relative to the particle-precipitating region. At 23:00 UT when the electric field exhibited a peak, Troms $\emptyset$ was located on the pole side of the arc-like absorption structure, indicating that the large electric field was measured in the low electron-density region. This asymmetry near the auroral arc has been reported by many researchers (de la Beaujardiere et al., 1977, 1981; Evans et al., 1977; Maynard et al., 1977; Stiles et al., 1980; Marklund et al., 1982; Ziesolleck et al., 1983; Opgenoorth et al., 1990; Doe et al., 1993; Aikio et al., 1993, 2002; Carlson et al., 1998; Johnson et al., 1998). On the other hand, at 22:00 UT when a small peak occurred in the particle heating rate, there was no notable absorption in the field-of-view of the imaging riometer. At 00:00 UT, when the second small peak occurred, Troms $\varnothing$ was in the weak absorption region. Some particle heating rates overcame $\Sigma_{p} E^{2}$, for example, near 00:30 UT on 10 September. The particle heating rate can exceed the Joule heating rate when precipitating high-energy particles (Evans et al., 1977; Wedde et al., 1977; Marklund, 1984). While particle heating may modulate winds more effectively than Joule heating in the lower thermosphere, this is not the case in the experiment because of the significantly small particle heating rate.

The vertical neutral-wind speed from 19:00 to 02:00 UT varies with larger amplitudes than amplitude variations for other intervals. Wind-data gaps which appeared from 14:00 to 19:00 UT on 9 September and from 02:00 to 08:00 UT on 10 September are due to the very low SNR of the remote-site data sets in the $E$-region. There is no data gap in the electric field and the heating rates because these values are calculated using only Troms $\emptyset$ radar data and $F$-region data. Vertical neutral-wind speeds at 114 and $120 \mathrm{~km}$ near 21:00 UT show negative or downward motions of -18 and $-45 \mathrm{~m} \mathrm{~s}^{-1}$, respectively. Vertical ion speeds at these heights have signatures similar to those of neutral winds. This suggests that the second term on the right-hand-side of Eq. (1) has few effects on the calculated vertical neutral-wind speed for this time interval, and that downward ion motions are caused by the drag of neutrals by collisions. When the height-integrated passive-energy deposition rate $\left(\Sigma_{p} E^{2}\right)$ starts to increase near 22:00 UT, vertical neutral-wind speeds in this height range are about $0 \mathrm{~m} \mathrm{~s}^{-1}$. When the value of $\Sigma_{p} E^{2}$ peaks at 23:00 UT, vertical neutral-wind speeds show the largest upward speed found in this experiment ( 38 and $85 \mathrm{~m} \mathrm{~s}^{-1}$ at 114 and $120 \mathrm{~km}$, respectively), although direction of the vertical ion speed remains downward. This discrepancy between neutral and ion vertical speeds suggests that ions are accelerated downward although neutral winds drag ions upward by collisions for this time interval.

Vertical neutral-wind speeds at $109 \mathrm{~km}$ also exhibit temporal variations similar to, but with smaller amplitudes than at 114 and $120 \mathrm{~km}$, although there are no good-quality data near 21:00 UT. From 00:00 to 02:00 UT, the vertical neutralwind speeds at 109, 114, and $120 \mathrm{~km}$ are downward, although the vertical ion speeds at these heights are approximately $0 \mathrm{~m} \mathrm{~s}^{-1}$. At that time $\Sigma_{p} E^{2}$ decreases considerably from the previous level. The relationships between vertical ion and neutral-wind speeds from 00:00 to 02:00 UT are notably different from those relationships around 21:00 UT. These sudden large variations from 19:00 to 02:00 UT are not seen during other time periods. Ionospheric data from $106 \mathrm{~km}$ are too sparse to discuss in the manuscript.

Horizontal components of the neutral-wind velocity from 19:00 to 02:00 UT also show interesting temporal variations as seen in Fig. 2. The northward and eastward components are drawn with thick blue and red lines, respectively. Estimated errors of the northward component are illustrated by gray shading at all times and heights (not shown here for the eastward component because the magnitude is almost the same as that for the northward component). The mean errors $\pm 1 \sigma$ for both components between 19:00 and 02:00 UT are also presented. The northward and eastward components of the ion velocity are shown with thin blue and red lines, respectively. Before increases in $\Sigma_{p} E^{2}$ begin, the meridional neutral-winds (thick blue line) at 114 and $120 \mathrm{~km}$ near 21:00 UT are equatorward. The meridional ion speeds (thin blue line) exhibit trends similar to those of the meridional neutral-winds, and ions are considered to be dragged by neutrals. As $\Sigma_{p} E^{2}$ increases near 23:00 UT, the meridional neutral winds at these heights dramatically change their direction from equatorward to poleward, although direction of the meridional ion speed remains equatorward. The meridional neutral-wind becomes equatorward again as $\Sigma_{p} E^{2}$ decreases 


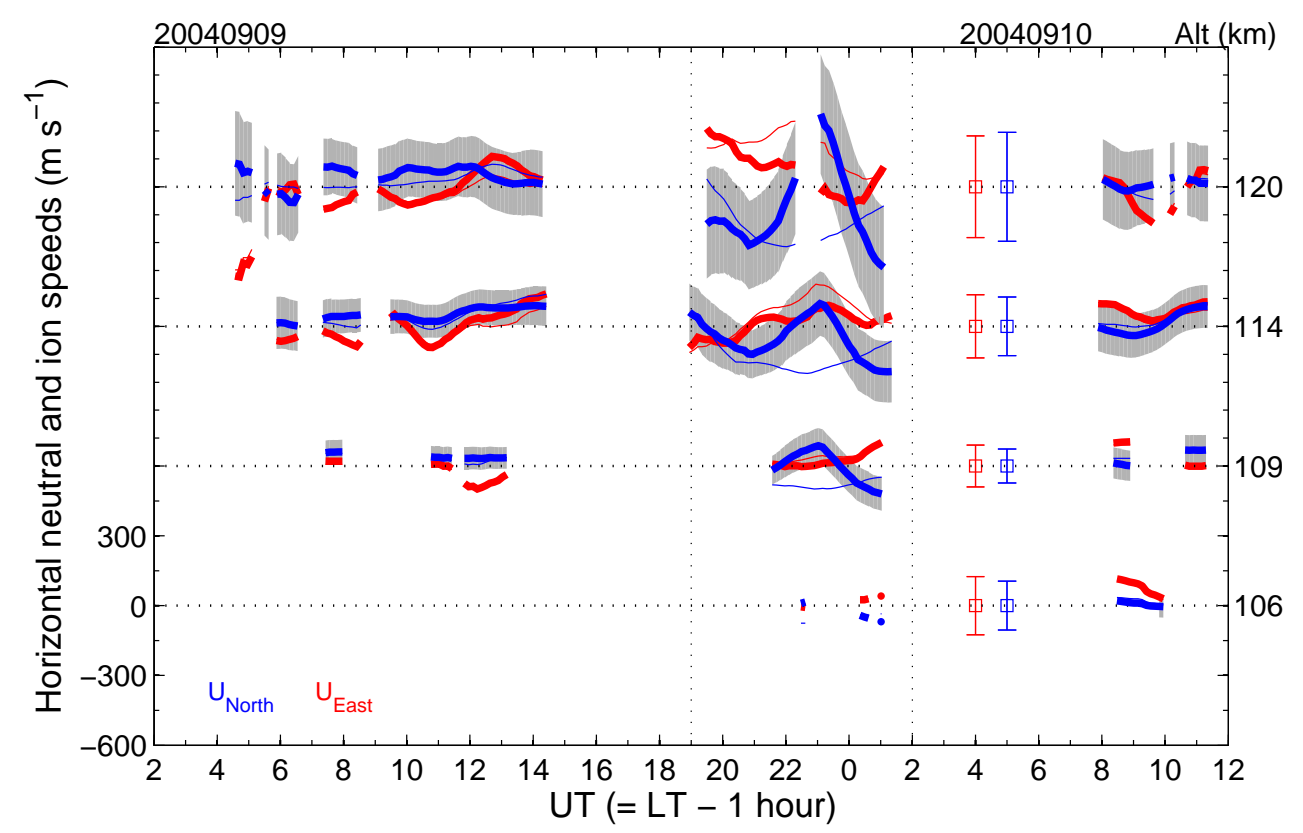

Fig. 2. Temporal variations in northward (blue) and eastward (red) components of the neutral-wind (thick curve) and the ion (thin curve) velocities measured with the EISCAT KST UHF radar on 9-10 September 2004. The vertical bar at each height is the mean error value $\pm 1 \sigma$ of the neutral-wind velocity from 19:00 to 02:00 UT. The error bars of the northward neutral-wind speed at individual times are also illustrated by gray shading above and below the line. Horizontal dotted lines are drawn at $0 \mathrm{~m} \mathrm{~s}^{-1}$ at each height. Vertical dotted lines are plotted at 19:00 UT on 9 September and 02:00 UT on 10 September 2004. All values are calculated using running-averaged data with a 64-min boxcar window length.

between 00:00 and 02:00 UT. While direction of the meridional ion speed is equatorward for this time interval, differences from the meridional neutral-wind speed are considerably larger than those differences between 20:00 and 22:00 UT. The zonal neutral-wind speed (thick red line) at each height from 19:00 to 02:00 UT varies less with time, and there is no significant difference between ion and neutral motions, although the difference at $120 \mathrm{~km}$ looks larger than differences at other heights.

Temporal variations at $109 \mathrm{~km}$ are similar to those at 114 and $120 \mathrm{~km}$. Such sudden direction and magnitude changes are not seen for other periods of the experiment. When $\Sigma_{p} E^{2}$ is not significantly enhanced (before 19:00 UT on 9 September and after 02:00 UT on 10 September), the horizontal winds vary with smaller amplitudes than amplitudes of estimated errors. Amplitude differences between quiet and moderately-disturbed periods are conspicuous, in particular for the meridional component.

Results in Figs. 1 and 2 suggest that winds in the lower thermosphere from 109 to $120 \mathrm{~km}$ (about two scale heights) were accelerated obliquely upward in the poleward direction near 23:00 UT. The acceleration direction is estimated to be approximately $80^{\circ}$ off-vertical in the poleward direction. Amplitudes of the neutral-wind velocity are height dependent; amplitudes are smaller at lower altitudes than at higher ones.
It is also notable that patterns of temporal variations in the vertical neutral-wind speed are similar to patterns of temporal variations in the meridional wind speed for the moderately-disturbed period, although the amplitudes differ. This similarity suggests that a single physical process is responsible for both. It is tempting to suggest that the similarity is caused by field-aligned motions of ions dragged by the meridional neutral wind; that is, vertical neutral-wind speeds shown in Fig. 1 are not individual thermospheric motions, but are just a projection of the field-aligned ion velocity component in the vertical direction. This hypothesis is, however, not correct because poleward (equatorward) neutral winds cause downward (upward) field-aligned ion motions due to equatorward tilting of the geomagnetic field line at Troms $\varnothing$, although vertical neutral-wind speeds derived are upward (downward) when most of meridional neutral-wind speeds are poleward (equatorward).

\section{Discussion}

\subsection{A physical process for generating wind variations}

Energy dissipation associated with enhancements of the electric field at high latitudes can cause thermal expansions, which significantly modulate lower-thermospheric winds. The horizontal pressure gradient depends on the location of 
(a) IMAGE Magnetometer Network

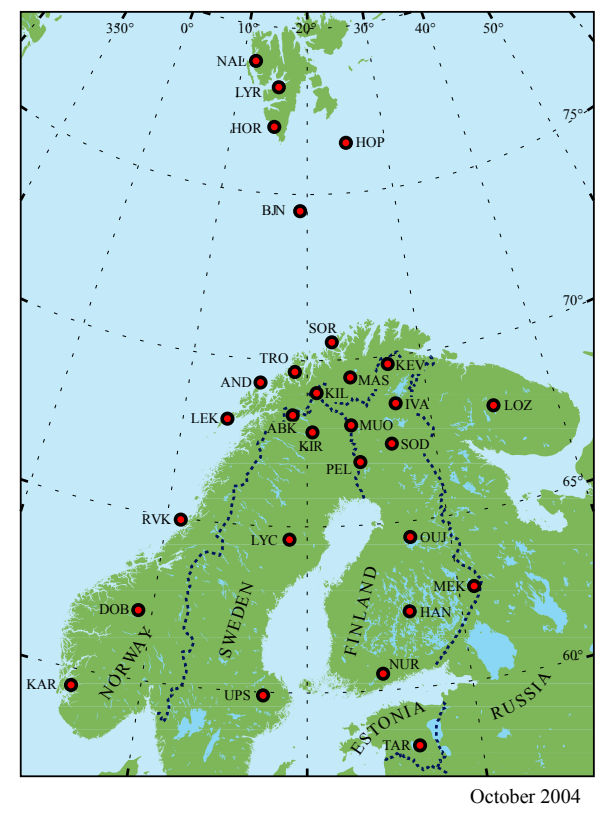

(b) IMAGE magnetometer network 2004-09-09

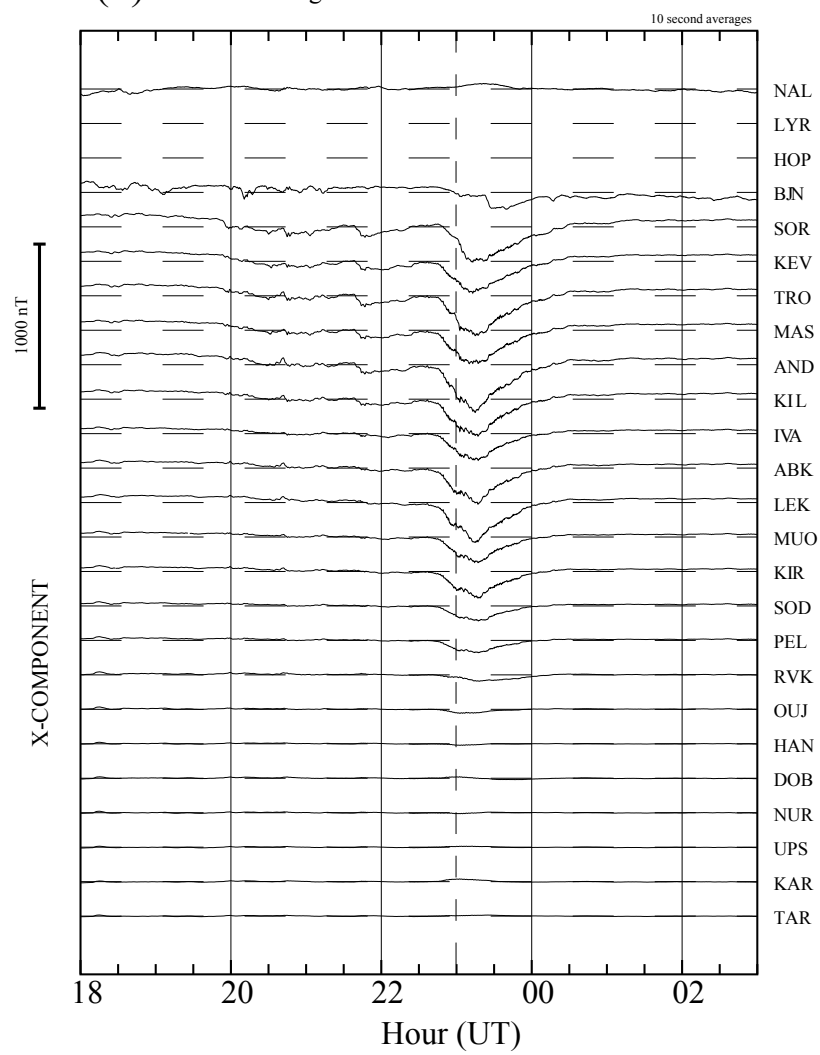

(c) IMAGE magnetometer network 2004-09-09

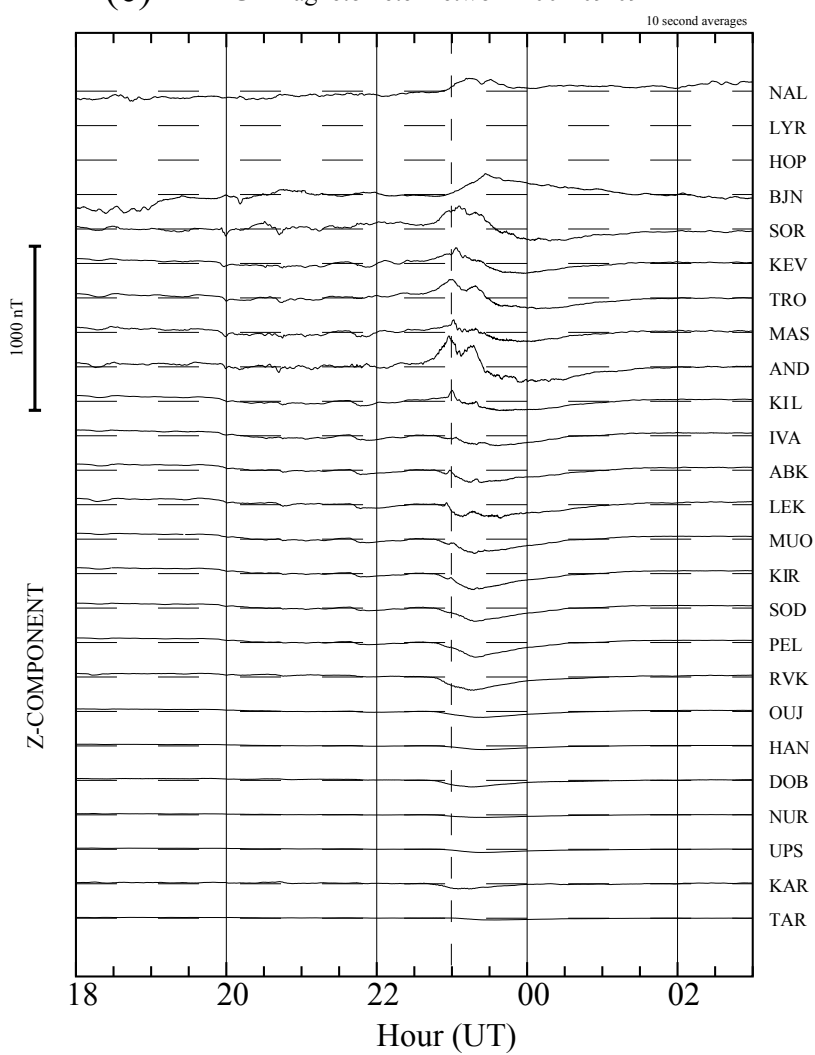

Fig. 3. (a) Map of the IMAGE magnetometer stations in northern Scandinavia. Temporal variations in (b) x-component and (c) z-component of the geomagnetic field measured from 18:00 UT on 9 September to 03:00 UT on 10 September 2004 using the IMAGE magnetometer chain. These figures are prepared using 10-s averaged data. Vertical dashed line marks 23:00 UT on 9 September 2004. These figures were prepared at the IMAGE web page (http://www.ava.fmi.fi/image/). 
the observation position relative to the heated region. For the moderately-disturbed period of the EISCAT experiment, the IMAGE (International Monitor for Auroral Geomagnetic Effects) magnetometers show that the horizontal ionospheric current exhibits a peak about $80 \mathrm{~km}$ to the equatorward side of Troms $\varnothing$ (TRO) when the maximum passive-energy deposition rate occurs at 23:00 UT. Measurements were made at 13 magnetometer stations; as reference for the readers, the location of each station is shown in Fig. 3a. Figure $3 \mathrm{~b}$ and $\mathrm{c}$ show temporal variations in $\mathrm{x}$ - (geographically northward) and z- (downward) components, respectively, of the geomagnetic field measured from 18:00 UT on 9 September to 03:00 UT on 10 September 2004 at individual stations. While deviations in the magnetometer data are mainly caused by Hall currents, which dissipate no energy, we can estimate the location of the ionospheric heated region because the Hall current is a function of the electric field. The electric field is a major term in the equation describing the Joule heating rate. Magnetometer data show notable enhancements around 23:00 UT when $\Sigma_{p} E^{2}$ has a peak as shown in Fig. 1. Negative deviations or westward ionospheric currents are obviously seen near 23:00 UT in data from 13 stations (Fig. 3a) in northern Scandinavia; the most northern and southern of the 13 stations are Sørøya (SOR) and Pello (PEL), respectively. Magnitudes of the negative deviation at four southern stations (Muonio (MUO), Kiruna (KIR), Sodankylä (SOD), and PEL) seem to be smaller than at the other nine stations. Negative deviation magnitudes at the other nine stations are almost the same, although the stations are located at different longitudes. The z-components at six northern stations (SOR, Kevo (KEV), TRO, Masi (MAS), Andenes (AND), and Kilpisjärvi (KIL)) clearly show positive deviations at that time. However, the magnitude of the positive deviation at KIL is notably small. At all seven southern stations, the zcomponents have negative deviations. These magnetometer results suggest that the horizontal ionospheric current near 23:00 UT flows westward with a peak around KIL located about $80 \mathrm{~km}$ southeast of Troms $\varnothing$ (Rostoker et al., 1976), and that the westward ionospheric current is aligned parallel to an L-shell. Therefore it is considered that the center of the heated region is also located there, and the heated area is also aligned parallel to the L-shell. In this case, the pressure gradient over Troms $\varnothing$ must be directed equatorward for the moderately-disturbed period. This idea qualitatively supports experimental results that the meridional neutral-wind speed changes from equatorward to poleward; its maximum poleward speed occurs at 23:00 UT, after which the wind returns to equatorward in association with a decrease in the heating event from 00:00 to 02:00 UT (see Figs. 1 and 2).

The discussion above can be accepted with some confidence. However, a quantitative understanding of whether the Joule and particle heating energies are sufficiently abundant to cause such large vertical motions in the lower thermosphere remains as a fundamental question. Hays et al. (1973) presented a simple way of estimating the vertical speed caused by "vertical" thermal expansion, in which all deposited energies are dissipated for thermospheric expansions in the vertical direction. The calculation under the first law of thermodynamics provided a vertical speed of $1-10 \mathrm{~cm} \mathrm{~s}^{-1}$ at the $120-\mathrm{km}$ level. This value is much smaller by several orders of magnitude than observed vertical speeds.

However, vertical wind speeds can become larger than calculated above if the isobar is vertically tilted and winds flow on the tilted isobar. In this case "vertical wind" is the geographically vertical component of the neutral wind flowing on the tilted isobar. To evaluate this quantitatively we estimate the "vertical wind" by applying a method similar to that of Hays et al. (1973) but allowing deposited energy to be transferred to horizontal thermal expansions.

The first law of thermodynamics gives the rate of change of internal energy, $\eta$, as

$\eta=\frac{d Q}{d t}-\frac{d \bar{W}}{d t}$,

where

$\frac{d Q}{d t}=N_{m} C_{p} \frac{d T}{d t}=N_{m} C_{p} \frac{d T}{d l} \frac{d l}{d t}=N_{m} C_{p} \frac{d T}{d l} U_{l}$

is the rate of heat gained per unit volume, $N_{m}$ is the mass density of neutrals, $C_{p}$ is the specific heat at constant pressure, $T$ is the temperature of neutrals, and $U_{l}$ is the wind flowing on the isobar in direction $l$. Here note that $l$ is parallel to surface of the tilted isobar.

$$
\frac{d \bar{W}}{d t}=\frac{d P}{d t}=\frac{d P}{d l} \frac{d l}{d t}=\frac{d P}{d l} U_{l}
$$

is the rate at which work is done per unit volume, and $P$ is the pressure. Precisely speaking $P$ also has some gradients in the direction perpendicular to $l$ or the isobar; but since the wind flux across the isobar, which may be called as omega wind (Fuller-Rowell, 1984), is considered to be much smaller than the $l$ component, the equations in this paper will be solved only on the surface of the isobar. Substituting Eqs. (3) and (4) into Eq. (2) gives $d T / d l$ as

$$
\frac{d T}{d l}=\frac{\eta}{N_{m} U_{l}\left(C_{p}-k /\langle m\rangle m_{p}\right)},
$$

assuming $P=N_{m} k T /\langle m\rangle m_{p}$, where $<m>$ and $m_{p}$ are the mean neutral mass and the proton mass, respectively, and $k$ is the Boltzmann constant. The gradient of $N_{m}$ along $l$ is assumed to be zero $\left(d N_{m} / d l=0\right)$ here. All parameters on the right-hand-side of Eq. (5) are given as the constant or as the result of EISCAT observation. In this calculation $\eta$ is $10^{-6} \mathrm{~J} \mathrm{~m}^{-3} \mathrm{~s}^{-1}, N_{m}$ is $8 \times 10^{-8} \mathrm{~kg} \mathrm{~m}^{-3}, C_{p}$ is $996 \mathrm{~J} \mathrm{~K}^{-1} \mathrm{~kg}^{-1}$, and $\langle m>$ is 30 a.m.u. The horizontal neutral-wind speed is, for example, $90 \mathrm{~m} \mathrm{~s}^{-1}$ at $109 \mathrm{~km}$ at 23:00 UT on 9 September 2004 (see Fig. 2). $U_{l}$ is different from the horizontal speed; but if $U_{l}$ is almost equivalent to $90 \mathrm{~m} \mathrm{~s}^{-1}, d T / d l$ at $109 \mathrm{~km}$ is $1.93 \times 10^{-4} \mathrm{~K} \mathrm{~m}^{-1}$. Since 
Table 1. Summary of estimated $d T / d l$ (third column from left) and $U_{z}$ (fourth column) from Eq. (5) at 109, 114, and $120 \mathrm{~km}$ heights. These values were calculated using EISCAT measurements conducted on 9 September 2004 at 23:00 UT. The last column shows the observed vertical-wind speed as a reference.

\begin{tabular}{ccccc}
\hline $\begin{array}{c}\text { Altitude } \\
(\mathrm{km})\end{array}$ & $\begin{array}{c}\text { Assumed } U_{l} \\
\left(\mathrm{~m} \mathrm{~s}^{-1}\right)\end{array}$ & $\begin{array}{c}d T / d l \\
\left(\mathrm{~K} \mathrm{~m}^{-1}\right)\end{array}$ & $\begin{array}{c}U_{z} \\
\left(\mathrm{~m} \mathrm{~s}^{-1}\right)\end{array}$ & $\begin{array}{c}\text { Observed } U_{z} \\
\left(\mathrm{~m} \mathrm{~s}^{-1}\right)\end{array}$ \\
\hline 109 & 90 & $1.93 \times 10^{-4}$ & 1.8 & 25 \\
114 & 127 & $2.73 \times 10^{-4}$ & 2.4 & 38 \\
120 & 312 & $2.22 \times 10^{-4}$ & 4.5 & 85 \\
\hline
\end{tabular}

the estimated distance from Troms $\varnothing$ to the heat source region is $80 \mathrm{~km}$, the temperature difference between these locations is $15.4 \mathrm{~K}\left(=1.93 \times 10^{-4} \times 80 \times 10^{3}\right)$. The temperature difference of $15.4 \mathrm{~K}$ at $109 \mathrm{~km}$ height corresponds to a $1.57 \mathrm{~km}$ height difference according to the MSIS model. Thus the elevation angle of the isobar can be estimated as $1.12^{\circ}\left(=\tan ^{-1}(1.57 / 80)\right)$. Since $U_{l}$ is here assumed to be equal to $90 \mathrm{~m} \mathrm{~s}^{-1}, U_{z}$ becomes $1.8 \mathrm{~m} \mathrm{~s}^{-1}$. The same calculation has been performed for the 114 and $120 \mathrm{~km}$ heights, and the results are summarized in Table 1. The estimated vertical wind speeds are more than two orders of magnitude larger than predicted by Hays et al. (1973), but smaller than observed speeds by one order of magnitude. To reproduce the observed vertical-wind speed, $d T / d l$ should be approximately one order of magnitude larger than the values in the table. However, $d T / d l$ estimated with the CTIP (Coupled Thermosphere/Ionosphere Plasmasphere) model (e.g. Fuller-Rowell et al., 1996) is $5 \times 10^{-6} \mathrm{~K} \mathrm{~m}^{-1}$ at a $120 \mathrm{~km}$ height at 00:00 UT on 10 September (not shown here).

Results from simulation studies of the vertical wind in the lower thermosphere (e.g. Sun et al., 1995; Shinagawa and Oyama, 2006) are inconsistent with the observation results shown here and from the FPIs. Most thermospheric-wind simulations show no significant variations in either vertical or horizontal winds below $120 \mathrm{~km}$ when the heating rate is at the same level as observed. However, previous FPI observations at a wavelength of $557.7 \mathrm{~nm}$ reported lower-thermospheric vertical winds at auroral latitudes with amplitudes larger than $40 \mathrm{~m} \mathrm{~s}^{-1}$ (Peteherych et al., 1985; Smith and Hernandez, 1995; Ishii, 2005), almost same amplitude as the observation result shown in Fig. 1 and, in sharp contrast, much larger than amplitudes predicted by model calculations. The explanation for the inconsistency between observed and simulated values is an important question that remains to be answered in future.

On the other hand, it is particularly noteworthy that such large vertical winds were previously observed with two individual instruments, FPI and the IS radar, and that vertical neutral-wind speeds in this paper were notably large for these heights. These large vertical speeds provide further insights into the thermospheric composition through chemical reactions and energy/momentum balance in the thermosphereionosphere coupled system. Variations in the thermospheric density due to vertical motions lead uncertainties in the ionneutral collision frequency and therefore in the neutral-wind calculation using Eq. (1). The effects of vertical mixing of the thermospheric gases due to vertical motions will be discussed in Sect. 4.2.

Some publications using data from the FPI (wavelength = $630.0 \mathrm{~nm}$ ) addressed the relationships between the verticalwind direction at $F$-region heights and the relative location of the auroral oval (Crickmore et al., 1991; Innis et al., 1996, 1997), reporting many measurements of upward (downward) speed at the poleward (equatorward) side of the oval. Since the thermospheric horizontal wind at $F$-region heights generally blows equatorward at night due to the global pressure gradient between the dayside and nightside hemispheres, the relationship is consistent with a hypothesis of upward displacement of the heated air parcel on the upstream side followed by downward displacement on the downstream side (Smith, 2000). This hypothesis presumes that the external force associated with thermospheric heating does not change the direction of the background horizontal wind even in the horizontally localized area. This hypothesis may contradict the results presented in this paper because the meridional wind speed at $E$-region heights dramatically changed its direction and magnitude, as shown in Fig. 2, at the same time that the upward speed increased, although the neutral density and the energy dissipation rate per unit mass are much larger and smaller, respectively, in the lower thermosphere than at $F$-region heights. While evidence of meso-scale structure in the thermospheric-wind dynamics at high latitudes has been reported from analyses of the horizontal component of neutral and ion velocities (Aruliah and Griffin, 2001; Aruliah et al., 2005), generation of large vertical thermospheric motions should also be inspected with a particular focus on mesoscale phenomena.

4.2 Wind uncertainty due to model dependencies of the ion-neutral collision frequency

The neutral-wind velocity calculated using IS-radar data is dependent on the ion-neutral collision frequency, which is estimated using density data from the MSIS model. Values of the MSIS neutral density may differ from real values in the thermosphere, especially during disturbed periods. This section discusses effects of the model-dependent ion-neutral collision frequency on the neutral-wind velocity.

Specifically, we cannot precisely determine the thermospheric-density modulation due to the vertical motions, even if the vertical neutral-wind speed is derived from IS-radar data. This is because the neutral-wind velocity estimated using IS-radar data is a function of the ion-neutral collision frequency. The available method presumes plausible thermospheric-density variations; it 


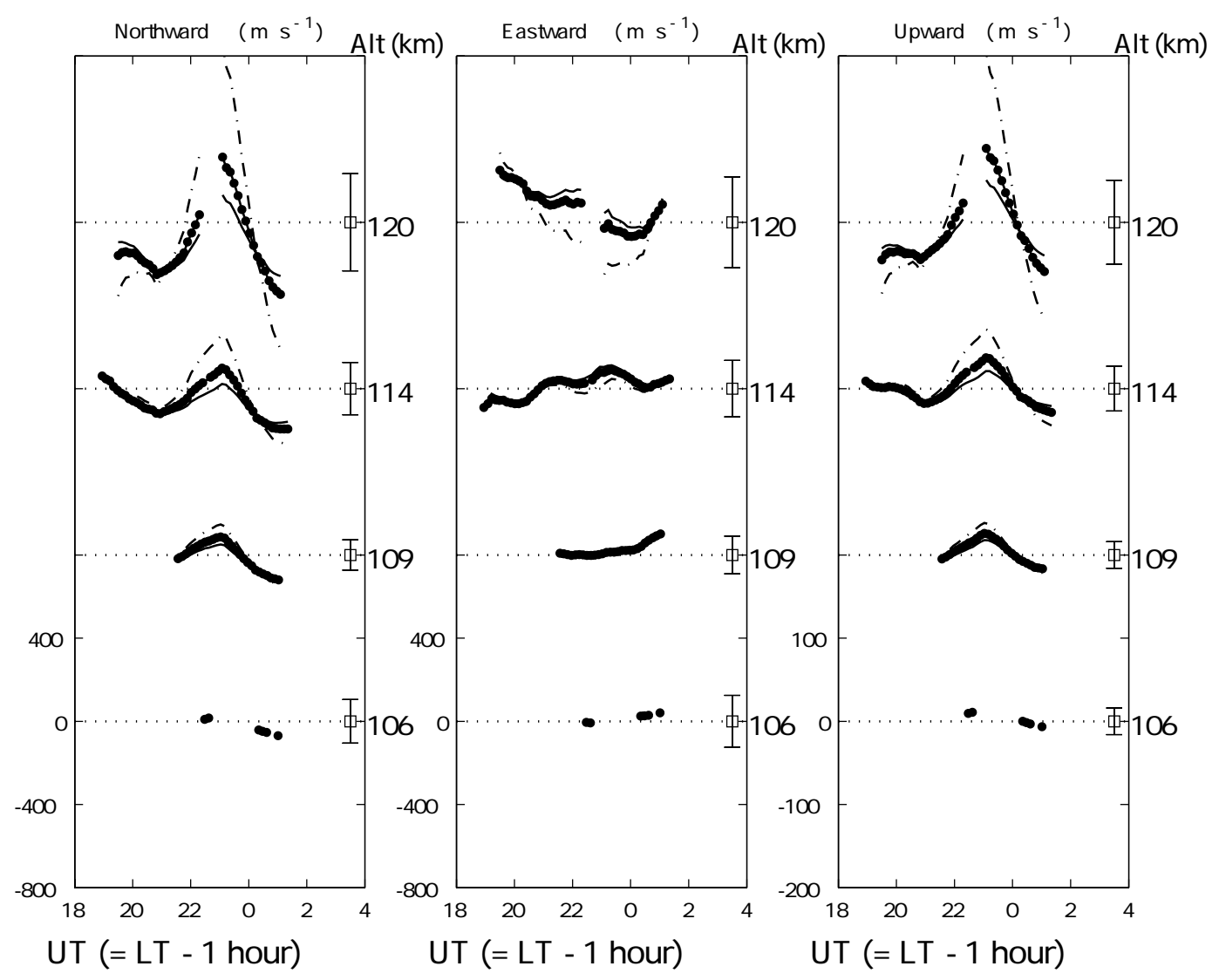

Fig. 4. Temporal variations in northward (left panel), eastward (middle panel), and upward (right panel) components of the neutral-wind velocity calculated with three kinds of neutral density data; original MSIS-model value (solid curve with dots), and 50\% increase (solid curve) and decrease (dash-dotted curve) at $120 \mathrm{~km}$ height from the original MSIS-model value (see text for details). The vertical bar at each height is the mean error value $\pm 1 \sigma$ for this time interval.

calculates the ion-neutral collision frequency, then recalculates the neutral-wind velocity by substituting the modified ion-neutral collision frequency. This method was applied in our previous paper (Oyama et al., 2005b), in which we suggest that the thermospheric density at $121 \mathrm{~km}$ varies by +34 and $-48 \%$ of the original MSIS-model value for upward and downward wind cases, respectively. These variations are reasonable; experimental evidence suggests that the MSIS density changes by a factor of two between geomagnetically quiet and disturbed days (Richards and Wilkinson, 1998). In this paper we assume two types of height profiles; $50 \%$ increase/decrease of the original MSIS value at $120 \mathrm{~km}$ and no changes at $100 \mathrm{~km}$. The modulation ratio from 100 to $120 \mathrm{~km}$ is changed smoothly with height.

Figure 4 shows temporal variations in three components (northward, eastward, and upward from left to right panels) of the neutral-wind velocity calculated using original MSIS values (solid curve with dots) and two kinds of modulated MSIS density values (solid curve for $50 \%$ increase and dashdotted curve for 50\% decrease). The mean errors from 19:00 to 02:00 UT are illustrated at each height by the vertical bars.
To make the figure, data for the moderately-disturbed period (from 19:00 UT on 9 September to 02:00 UT on 10 September) are used because effects of the modulation during quiet periods on the neutral-wind calculation are smaller than effects during the moderately-disturbed period. For each component of the neutral-wind velocity below $109 \mathrm{~km}$, the differences among the results of the three calculations (original MSIS, $+50 \%$ and $-50 \%$ modulated MSIS) are smaller than the mean error value. On the other hand, the differences at 114 and $120 \mathrm{~km}$ are sometimes larger than the mean error value, in particular near 23:00 UT when the electric-field magnitude is large. This result suggests that the neutral-wind calculation below $109 \mathrm{~km}$ is more sensitive to measurement uncertainty in the IS-radar data than in the neutral-density modulation, but both are important above $114 \mathrm{~km}$. This result is consistent with results in our previous paper (Oyama et al., 2005b). 


\section{Summary and conclusions}

The tristatic measurement with the EISCAT KST UHF radar system was conducted on 9-10 September 2004 in order to estimate the neutral-wind velocity in the lower thermosphere for periods of moderate geomagnetic disturbance. The antenna-beam configuration was newly designed to minimize the estimated measurement error of the vertical neutral-wind speed in the lower thermosphere, and this method was available to simultaneously estimate the three wind-speed components (meridional, zonal, and vertical). The new method reduced the measurement error of the vertical-wind speed by approximately $40 \%$ from the traditional CP-1 method. The vertical neutral-wind speed in the height range from 109 to $120 \mathrm{~km}$ showed large upward motions in excess of $30 \mathrm{~m} \mathrm{~s}^{-1}$ in association with the ionospheric heating event from 19:00 to 02:00 UT on 9-10 September 2004 as shown in Fig. 1. The meridional neutral-wind velocity component suddenly changed direction from equatorward to poleward in association with the heating event. Large downward neutral-wind speeds in excess of $-30 \mathrm{~m} \mathrm{~s}^{-1}$ were also seen in Fig. 1 before and after the heating event. Discussion of the relative speed between ions and neutrals suggested that neutrals in the polar lower thermosphere can move downward at speeds in excess of a few $10 \mathrm{~m} \mathrm{~s}^{-1}$ without the in-situ forcing associated with enhancements of the electric field.

When large upward motions and sudden direction changes in the meridional wind were observed in the lower thermosphere, the IMAGE magnetometers showed that the horizontal ionospheric current had a peak on the equator side of Troms $\varnothing$. The direction of the pressure gradient associated with the current peak suggested obliquely upward acceleration of the lower-thermospheric winds in the poleward direction. To quantitatively understand this event, we estimated the vertical-wind speed assuming neutral-wind flows on a tilted isobar. While the estimated speed was two orders of magnitude larger than predicted by Hays et al. (1973), it was one order of magnitude smaller than observed with the EISCAT radar. Thus the physical mechanism responsible for generating such large vertical winds in the lower thermosphere is not yet understood.

This paper suggests that the energy exchange between the ionosphere and the lower thermosphere results in significant modulations in both horizontal and vertical motions in the lower thermosphere. Temporal variations in the lowerthermospheric wind during moderately-disturbed periods are height dependent. To understand these variations, appropriate height resolution smaller than at least the scale height is necessary. Previous studies of the lower-thermospheric vertical wind with FPI suggest that the vertical motion can be caused by divergent flow imposed by a driving force acting horizontally (Burnside et al., 1981; Smith and Hernandez, 1995). This process is a topic for future research. Height dependencies of the wind suggest that the momentum balance of the lower-thermospheric wind and quantitative rela- tionships between energy inputs and winds during disturbed periods should be further studied.

\section{Appendix A}

\section{Methodology to calculate the passive-energy deposition rate and the particle heating rate}

The Joule heating rate can be expressed as follows:

$$
\begin{aligned}
\boldsymbol{J} \cdot \boldsymbol{E}^{\prime} & =\sigma_{p}(\boldsymbol{E}+\boldsymbol{U} \times \boldsymbol{B})^{2} \\
& =\sigma_{p} E^{2}+\sigma_{p}|\boldsymbol{U} \times \boldsymbol{B}|^{2}-2 \sigma_{p} \boldsymbol{U} \cdot(\boldsymbol{E} \times \boldsymbol{B}),
\end{aligned}
$$

where $\sigma_{p}$ is the Pedersen conductivity. If the neutral wind blows in the same direction as the ion velocity but with a smaller speed, the sum of the second and the third terms in the right-hand-side of Eq. (A1) can be negative. In this case $\sigma_{p} E^{2}$ is larger than the Joule heating rate. If the neutralwind speed is considerably smaller than the ion speed, $\sigma_{p} E^{2}$ is almost equal to the Joule heating rate. These situations are likely in the polar ionosphere, and $\sigma_{p} E^{2}$ is available as an indicator to identify enhancements of the Joule heating rate.

The Pedersen conductivity can be expressed as (Brekke and Hall, 1988)

$\sigma_{p}=\frac{N_{e} q_{e}}{B}\left(\frac{\Omega_{e} v_{e n}}{\Omega_{e}^{2}+v_{e n}^{2}}+\frac{\Omega_{i} v_{i n}}{\Omega_{i}^{2}+v_{i n}^{2}}\right)$,

where $N_{e}$ is the electron density, $q_{e}$ is the electron charge, $\Omega_{e}$ and $\Omega_{i}$ are the electron and ion gyrofrequencies, respectively, and $v_{e n}$ and $v_{i n}$ are the electron-neutral and ion-neutral collision frequencies, respectively. In this paper the Pedersen conductivity is calculated using height-resolved ionospheric and thermospheric data from the Troms $\varnothing$ UHF radar and the MSIS model, respectively. The Pedersen conductivity is integrated from 95 to $330 \mathrm{~km}$ in order to calculate the heightintegrated passive-energy deposition rate, $\Sigma_{p} E^{2}$.

The height-integrated particle heating rate $Q_{p}\left(\mathrm{~W} \mathrm{~m}^{-2}\right)$ can be written as (Vickrey et al., 1982)

$Q_{p}=5.6 \times 10^{-7} \int_{95 \mathrm{~km}}^{160 \mathrm{~km}} \alpha_{\mathrm{eff}} N_{e}^{2} d z$,

where $\alpha_{\text {eff }}$ is the effective recombination coefficient $\left(\mathrm{m}^{3} \mathrm{~s}^{-1}\right), N_{e}$ is the electron density $\left(\mathrm{m}^{-3}\right)$, and $z$ is height $(\mathrm{km})$. The effective recombination coefficient employed in the paper can be written as

$\alpha_{\text {eff }}=2.5 \times 10^{-12} \exp \left(-\frac{z}{51.2}\right)$

between 95 and $160 \mathrm{~km}$. To calculate $Q_{p}$ using these equations we need to assume ionospheric homogeneity for one data-integration time unit, negligibly small ion-transport in the height-integrated region, and $35 \mathrm{eV}$ for ion-electron pair production. 

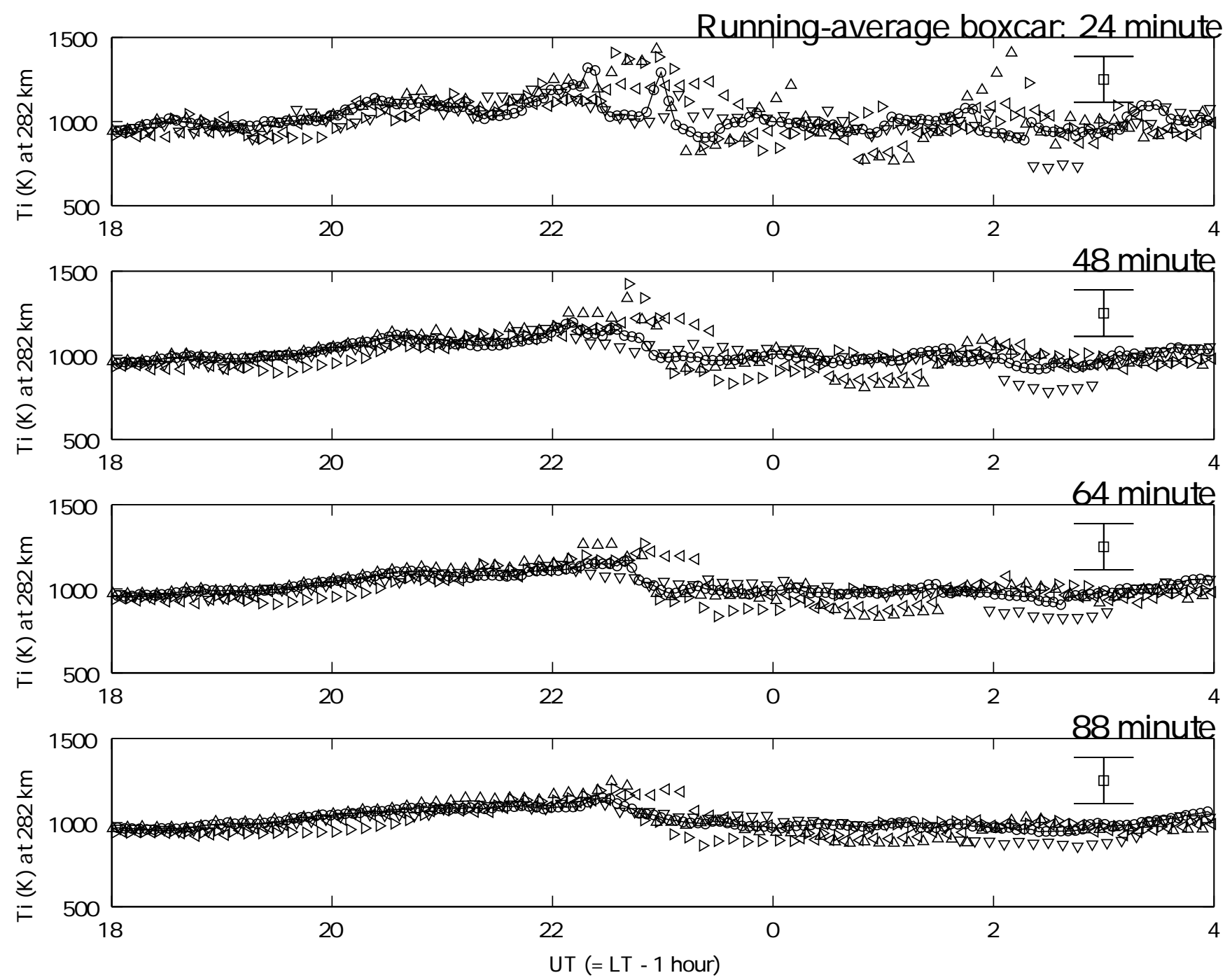

Fig. B1. Temporal variations in the ion temperature at $282 \mathrm{~km}$ height from 18:00 to 04:00 UT on 9-10 September 2004 during the EISCAT experiment. There are five kinds of ion temperature in each panel: data obtained for the tristatic measurement at $106 \mathrm{~km}$ (upward-pointing triangle), at $109 \mathrm{~km}$ (rightward-pointing triangle), at $114 \mathrm{~km}$ (downward-pointing triangle), at $120 \mathrm{~km}$ (leftward-pointing triangle), and at $282 \mathrm{~km}$ (solid curve with open circle). The running-average method with boxcar window lengths of 24, 48, 64, and 88 min (from top to bottom) is applied to each ion temperature. Vertical bar is the mean measurement uncertainty of the $F$-region ion temperature with $\pm 1 \sigma$ from 18:00 to 04:00 UT.

\section{Appendix B}

\section{Methodology for implementing the running average, taking into account ionospheric homogeneity for one IS-radar antenna sequence}

This section describes how to appropriately decide the shortest window length for the running average, taking into account spatiotemporal ionospheric homogeneity. Neutralwind estimation with the tristatic method employed in this paper needs assumptions of spatiotemporal homogeneity in the observed ionosphere for one IS-radar antenna sequence. Assumption of the temporal homogeneity is necessary due to non-simultaneous tristatic measurements in the $E$ - and $F$ regions. On the other hand, an assumption of spatial homogeneity is necessary due to magnetic field lines in the $E$ - and $F$-regions where the tristatic measurement was undertaken that differ from those at the geographically vertical beam transmitted from the Troms $\emptyset$ UHF radar. The electric field may have different values among neighboring magnetic field lines, even if it is temporally stable for one antenna sequence. The spatiotemporal assumption may therefore be wrong when the observed ionosphere has fine structures.

The ion temperature in the $F$-region is smoothed by applying a running-average method with several boxcar window 

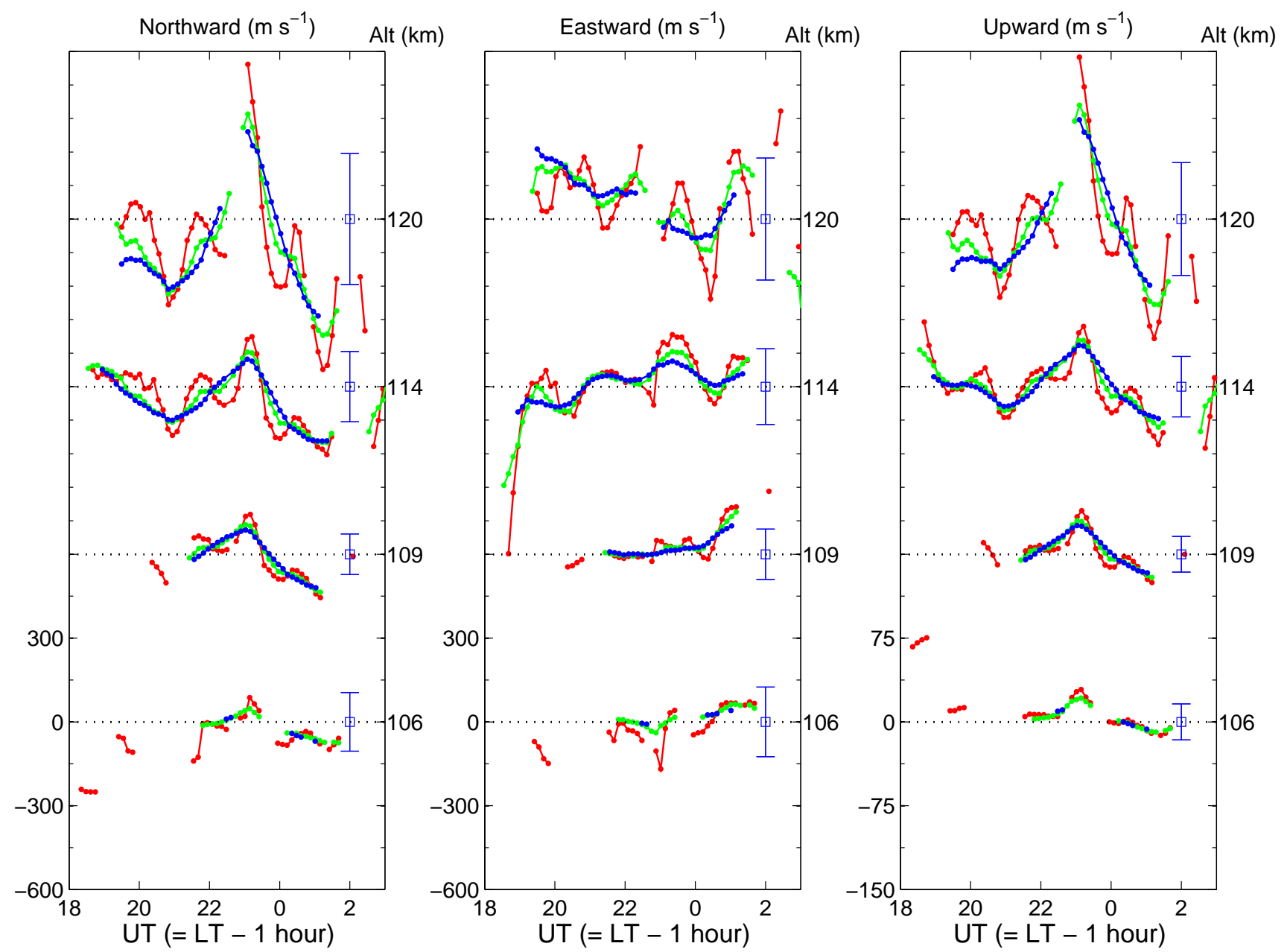

Fig. B2. Temporal variations in northward (left panel), eastward (middle panel), and upward (right panel) components of the neutral-wind velocity calculated using running-averaged data with the 24-, 48-, and 64-min boxcar window lengths (red, green, and blue, respectively). The vertical bars are the mean error for the 64-min case of each component at individual heights.

lengths in order to choose the best one. The reason for selecting the $F$-region ion temperature is mentioned below. There are several ionospheric parameters that are important for calculating the neutral wind using Eq. (1), and they may spatiotemporally vary during one antenna sequence. One such parameter is the electric field. While the electric field cannot be estimated when the tristatic measurement is conducted in the $E$-region, the ion temperature in the $F$-region is available as an alternative approach to investigate spatiotemporal variations in the electric field. This is because short-timescale fluctuations in the $F$-region ion temperature are quite sensitive to frictional heating.

Figure B1 shows temporal variations in the ion temperatures at $282 \mathrm{~km}$ height from 18:00 to 04:00 UT on 9-10 September 2004. These data are smoothed by the runningaverage method with 24-, 48-, 64-, and 88-min boxcar window lengths (from top to bottom panels of Fig. B1). Each panel is prepared by using five sets of $F$-region ion tem- perature, corresponding to values obtained for four $E$-region tristatic measurements at $106 \mathrm{~km}$ (upward-pointing triangle), $109 \mathrm{~km}$ (rightward-pointing triangle), $114 \mathrm{~km}$ (downwardpointing triangle), and $120 \mathrm{~km}$ (leftward-pointing triangle) and one $F$-region measurement at $282 \mathrm{~km}$ (solid curve with open circle). The mean measurement uncertainty is shown in the upper right corner in each panel, although the error bar is not sensitive to the boxcar window length. In the case of 24 and $48 \mathrm{~min}$ boxcar window lengths, some time intervals show larger distributions of the ion temperature than the mean measurement uncertainty, in particular from 22:00 to 00:00 UT. Such large distributions suggest that the ion temperature has significant temporal variations and/or spatial distribution in the $F$-region for one IS-radar antenna sequence. If this is the case, the electric field should also vary significantly, and assumptions of ionospheric homogeneity are not acceptable for the neutral-wind calculation. In cases of the 64 and 88-min boxcar window lengths, the 
distributions are smaller than the mean measurement uncertainty for this time interval, although they are relatively large from 22:00 to 00:00 UT. Therefore assumptions of ionospheric homogeneity are acceptable for the neutral-wind calculation using these boxcar window lengths. This is the reason that the 64-min boxcar window length was employed in this paper.

Figure B2 shows dependencies of the calculated neutralwind velocity on the boxcar window length. The boxcar window lengths used here are 24 (red), 48 (green), and 64 (blue) min. The mean error bars for the 64-min case are illustrated for each component at all heights (The mean error bars for the other cases are almost equivalent to the 64-min case). The gross features of the wind smoothed with the 24-min boxcar window length are captured by the other cases. Winds with the 24-min boxcar window length are characterized by more spiky temporal variations with larger amplitudes. It is, however, noted that spiky variations can be caused not only by real thermospheric motions but also by unexpected contamination due to spatiotemporal inhomogeneity in the ionosphere/thermosphere during one antenna sequence. Since appropriate methodology has not yet been developed, nor abundant experimental evidence collected to allow us to conclude that the spiky variations in the $E$-region are real, the winds estimated with the 24- and 48-min boxcar window lengths are not discussed in this paper.

Acknowledgements. We are indebted to the director and staff of EISCAT for operating the facility and supplying the data. EISCAT is an International Association supported by China (CRIRP), Finland (SA), the Federal Republic of Germany (DFG), Japan (STEL and NIPR), Norway (NFR), Sweden (VR) and the United Kingdom (PPARC). The EISCAT KST radar experiment on 9-10 September 2004 was conducted using Japan, France, and Norway's SP time. We thank the institutes who maintain the IMAGE magnetometer array. The authors are thankful to the Community Coordinated Modeling Center at NASA Goddard Space Flight Center for the CTIP model simulations. The data originated from the Imaging Riometer for Ionospheric Studies (IRIS), operated by the Department of Communications Systems at Lancaster University (UK) in collaboration with the Sodankylä Geophysical Observatory, and funded by the Science and Technology Facilities Council (STFC). This research was supported by Grant 2007-1136 from Yamada Science Foundation. This research has been partly supported by a Grant-in-Aid for Scientific Research B (16340146, 17340145, and 18403010) by the Ministry of Education, Science, Sports and Culture, Japan.

Topical Editor M. Pinnock thanks M. J. Kosch and another anonymous referee for their help in evaluating this paper.

\section{References}

Aikio, A. T., Opgenoorth, H. J., Persson, M. A. L., and Kaila, K. U.: Ground-based measurements of an arc-associated electric field, J. Atmos. Terr. Phys., 55(4/5), 797-808, 1993.

Aikio, A. T., Lakkala, T., Kozlovsky, A., and Williams, P. J. S.: Electric fields and currents of stable drifting auroral arcs in the evening sector, J. Geophys. Res., 107(A12), 1424, doi:10.1029/2001JA009172, 2002.

Aruliah, A. L. and Griffin, E. M.: Evidence of meso-scale structure in the high-latitude thermosphere, Ann. Geophys., 19, 3646, 2001, http://www.ann-geophys.net/19/36/2001/.

Aruliah, A. L., Griffin, E. M., Aylward, A. D., Ford, E. A. K., Kosch, M. J., Davis, C. J., Howells, V. S. C., Pryse, S. E., Middleton, H. R., and Jussila, J.: First direct evidence of meso-scale variability on ion-neutral dynamics using co-located tristatic FPIs and EISCAT radar in Northern Scandinavia, Ann. Geophys., 23, 147-162, 2005, http://www.ann-geophys.net/23/147/2005/.

Brekke, A. and Rino, C. L.: High-resolution altitude profiles of the auroral zone energy dissipation due to ionospheric currents, J. Geophys. Res., 83, 2517-2524, 1978.

Brekke, A. and Hall, C.: Auroral ionospheric quiet summer time conductances, Ann. Geophys., 6, 361-376, 1988, http://www.ann-geophys.net/6/361/1988/.

Burnside, R. G., Herrero, F. A., Meriwether Jr., J. W., and Walker, J. C. G.: Optical observations of thermospheric dynamics at Arecibo, J. Geophys. Res., 86, 5532-5540, 1981.

Caccia, J.-L., Guénard, V., Benech, B., Campistron, B., and Drobinski, P.: Vertical velocity and turbulence aspects during Mistral events as observed by UHF wind profilers, Ann. Geophys., 22, 3927-3936, 2004, http://www.ann-geophys.net/22/3927/2004/.

Carlson, C. W., McFadden, J. P., Ergun, R. E., Temerin, M., Peria, W., Mozer, F. S., Klumpar, D. M., Shelley, E. G., Peterson, W. K., Moebius, E., Elphic, R., Strangeway, R., Cattell, C., and Pfaff, R.: FAST observations in the downward auroral current region: Energetic upgoing electron beams, parallel potential drops, and ion heating, Geophys. Res. Lett., 25(12), 2017-2020, 1988.

Crickmore, R. I., Dudeney, J. R., and Rodger, A. S.: Vertical thermospheric winds at the equatorward edge of the auroral oval, J. Atmos. Terr. Phys., 53(6/7), 485-492, 1991.

de la Beaujardiere, O., Vondrak, R., and Baron, M.: Radar observations of electric fields and currents associated with auroral arcs, J. Geophys. Res., 82(32), 5051-5062, 1977.

de la Beaujardiere, O., Vondrak, R., Heelis, R., Hanson, W., and Hoffman, R.: Auroral arc electrodynamic parameters measured by $\mathrm{AE}-\mathrm{C}$ and the Chatanika radar, J. Geophys. Res., 86(A6), 4671-4685, 1981.

Doe, R. A., Mendillo, M., Vickrey, J. F., Zanetti, L. J., and Eastes, R. W.: Observations of nightside auroral cavities, J. Geophys. Res., 98(A1), 293-310, 1993.

Evans, D. S., Maynard, N. C., Trøim, J., Jacobsen, T., and Egeland, A.: Auroral vector electric field and particle comparisons 2. Electrodynamics of an arc, J. Geophys. Res., 82, 2235-2249, 1977.

Fritts, D. C. and Yuan, L.: Measurement of momentum fluxes near the summer mesopause at Poker Flat, Alaska, J. Atmos. Sci., 46(16), 2569-2579, 1989.

Fritts, D. C., Hoppe, U.-P., and Inhester, B.: A study of the vertical motion field near the high-latitude summer mesopause during MAC/SINE, J. Atmos. Terr. Phys., 52(10/11), 927-938, 1990.

Fritts, D. C. and Hoppe, U.-P.: High-resolution measurements of vertical velocity with the European incoherent scatter VHF radar 2. Spectral observations and model comparisons, J. Geophys. 
Res., 100(D8), 16 827-16838, 1995.

Fujii, R., Nozawa, S., Matuura, N., and Brekke, A.: Study on neutral wind contribution to the electrodynamics in the polar ionosphere using EISCAT CP-1 data, J. Geophys. Res., 103(A7), 14 731-14 740, 1998.

Fujii, R., Nozawa, S., Buchert, S. C., and Brekke, A.: Statistical characteristics of electromagnetic energy transfer between the magnetosphere, the ionosphere, and the thermosphere, J. Geophys. Res., 104(A2), 2357-2366, 1999.

Fukao, S., Larsen, M. F., Yamanaka, M. D., Furukawa, H., Tsuda, T., and Kato, S.: Observations of a reversal in long-term average vertical velocities near the jet stream wind maximum, Mon. Weather Rev., 119, 1479-1489, 1991.

Fuller-Rowell, T. J.: A Two-dimensional, high-resolution, nestedgrid model of the thermosphere, 1 . Neutral response to an electric field "spike", J. Geophys. Res., 89(A5), 2971-2990, 1984.

Fuller-Rowell, T. J., Codrescu, M. V., Rishbeth, H., Moffett, R. J., and Quegan, S.: On the seasonal response of the thermosphere and ionosphere to geomagnetic storms, J. Geophys. Res., 101(A2), 2343-2353, 1996.

Hays, P. B., Jones, R. A., and Rees, M. H.: Auroral heating and the composition of the neutral atmosphere, Planet. Space Sci., 21, 559-573, 1973

Hedin, A. E.: Extension of the MSIS thermosphere model into the middle and lower atmosphere, J. Geophys. Res., 96(A2), 1159$1172,1991$.

Hoppe, U.-P. and Fritts, D. C.: High-resolution measurements of vertical velocity with the European incoherent scatter VHF radar 1. Motion field characteristics and measurement biases, J. Geophys. Phys., 100(D8), 16813-16 825, 1995.

Innis, J. L., Greet, P. A., and Dyson, P. L.: Fabry-Perot spectrometer observations of the auroral oval/polar cap boundary above Mawson, Antarctica, J. Atmos. Terr. Phys., 58(16), 1973-1988, 1996.

Innis, J. L., Dyson, P. L., and Greet, P. A.: Further observations of the thermospheric vertical wind at the auroral oval/polar cap boundary, J. Atmos. Solar-Terr. Phys., 59(16), 2009-2022, 1997.

Ishii, M., Oyama, S., Nozawa, S., Fujii, R., Sagawa, E., Watari, S., and Shinagawa, H.: Dynamics of neutral wind in the polar region observed with two Fabry-Perot Interferometers, Earth Planets Space, 51, 833-844, 1999.

Ishii, M., Conde, M., Smith, R. W., Krynicki, M., Sagawa, E., and Watari, S.: Vertical wind observations with two Fabry-Perot interferometers at Poker Flat, Alaska, J. Geophys. Res., 106, 10 537-10 551, 2001.

Ishii, M., Kubota, M., Conde, M., Smith, R. W., and Krynicki, M.: Vertical wind distribution in the polar thermosphere during Horizontal $E$ Region Experiment (HEX) campaign, J. Geophys. Res., 109, A12311, doi:10.1029/2004JA010657, 2004.

Ishii, M.: Relationship between thermospheric vertical wind and the location of ionospheric current in the polar region, Adv. Polar Upper Atmos. Res., 19, 63-70, 2005.

Johnson, M. L., Murphree, J. S., Marklund, G. T., and Karlsson, T.: Progress on relating optical auroral forms and electric field patterns, J. Geophys. Res., 103(A3), 4271-4284, 1998.

Kofman, W., Bertin, F., Röttger, J., Cremieux, A., and Williams, P. J. S.: The EISCAT mesospheric measurements during the CAMP campaign, J. Atmos. Terr. Phys., 46(6/7), 565-575, 1984.

Larsen, M. F., Röttger, J., and Holden, D. N.: Direct measurements of vertical-velocity power spectra with Sousy-VHF-radar wind profiler system, J. Atmos. Sci., 44(23), 3442-3448, 1987.

Marklund, G., Sandahl, I., and Opgenoorth, H.: A study of the dynamics of a discrete auroral arc, Planet. Space Sci., 30(2), 179197, 1982.

Marklund, G.: Auroral arc classification scheme based on the observed arc-associated electric field pattern, Planet. Space Sci., 32(2), 193-211, 1984.

Maynard, N. C., Evans, D. S., Maehlum, B., and Egeland, A.: Auroral vector electric field and particle comparisons 1 . Premidnight convection topology, J. Geophys. Res., 82(16), 2227-2234, 1977.

Mitchell, N. J. and Howells, V. St. C.: Vertical velocities associated with gravity waves measured in the mesosphere and lower thermosphere with the EISCAT VHF radar, Ann. Geophys., 16, 1367-1379, 1998,

http://www.ann-geophys.net/16/1367/1998/.

Mohan, K., Rao, D. N., Rao, T. N., and Raghavan, S.: Estimation of temperature and humidity from MST radar observations, Ann. Geophys., 19, 855-861, 2001, http://www.ann-geophys.net/19/855/2001/.

Nastrom, G. D., Peterson, M. R., Green, J. L., Gage, K. S., and Van Zandt, T. E.: Sources of gravity wave activity seen in the vertical velocities observed by the Flatland VHF radar, J. Appl. Meteorol., 29, 783-792, 1990.

Nozawa, S. and Brekke, A.: Studies of the E region neutral wind in the disturbed auroral ionosphere, J. Geophys. Res., 100(A8), 14717-14 734, 1995

Nozawa, S. and Brekke, A.: Studies of the auroral E region neutral wind through a solar cycle: Quiet days, J. Geophys. Res., 104(A1), 45-66, 1999.

Opgenoorth, H. J., Häggström, I., Williams, P. J. S., and Jones, G. O. L.: Regions of strongly enhanced perpendicular electric fields adjacent to auroral arcs, J. Atmos. Terr. Phys., 52(6-8), 449-458, 1990.

Oyama, S., Nozawa, S., Maeda, S., Murayama, Y., Fujii, R., and Shinagawa, H.: Field-aligned ion motions in the polar E-F transition region: Mean characteristics, J. Geophys. Res., 108(A8), 1334, doi:10.1029/2003JA009830, 2003.

Oyama, S., Watkins, B. J., Nozawa, S., Maeda, S., and Conde, M.: Vertical ion motions observed with incoherent-scatter radars in the polar lower ionosphere, J. Geophys. Res., 110, A04302, doi:10.1029/2004JA010705, 2005a.

Oyama, S., Watkins, B. J., Maeda, S., and Watermann, J.: Application of a new beam configuration to estimate lower thermospheric vertical velocities at high latitudes with monostatic incoherent-scatter radars, Radio Sci., 40, RS4005, doi:10.1029/2004RS003205, 2005b.

Peteherych, S., Shepherd, G. G., and Walker, J. K.: Observation of vertical $E$-region neutral winds in two intense auroral arcs, Planet. Space Sci., 33(8), 869-873, 1985.

Price, G. D. and Jacka, F.: The influence of geomagnetic activity on the upper mesosphere/lower thermosphere in the auroral zone, I. Vertical winds, J. Atmos. Terr. Phys., 53, 909-922, 1991.

Price, G. D., Smith, R. W., and Hernandez, G.: Simultaneous measurements of large vertical winds in the upper and lower thermosphere, J. Atmos. Terr. Phys., 57, 631-643, 1995.

Rastogi, P. K. and Bowhill, S. A.: Gravity waves in the equatorial mesosphere, J. Atmos. Terr. Phys., 38, 51-60, 1976. 
Revathy, K., Nair, S. R. P., and Murthy, B. V. K.: Deduction of temperature profile from MST radar observations of vertical wind, Geophys. Res. Lett., 23(3), 285-288, 1996.

Richards, P. G. and Wilkinson, P. J.: The ionosphere and thermosphere at southern midlatitudes during the November 1993 ionospheric storm: A comparison of measurement and modeling, J. Geophys. Res., 103(A5), 9373-9389, 1998.

Rino, C. L., Brekke, A., and Baron, M. J.: High-resolution auroral zone E-region neutral wind and current measurements by incoherent scatter radar, J. Geophys. Res., 82, 2295-2304, 1977.

Rostoker, G., Sharma, R. P., and Hron, M. P.: Thermal plasma enhancements in the topside ionosphere and their relationship to the auroral electrojets, Planet. Space Sci., 24, 1081-1091, 1976.

Schlegel, K.: Auroral zone E-region conductivities during solar minimum derived from EISCAT data, Ann. Geophys., 6(1), 129138, 1988.

Shinagawa, H. and Oyama, S.: A two-dimensional simulation of thermospheric vertical winds in the vicinity of an auroral arc, Earth Planets Space, 58(9), 1173-1181, 2006.

Smith, R. W. and Hernandez, G.: Vertical winds in the thermosphere within the polar cap, J. Atmos. Terr. Phys., 57(6), 611620, 1995.

Smith, R. W.: The global-scale effect of small-scale thermospheric disturbances, J. Atmos. Solar-Terr. Phys., 62, 1623-1628, 2000.

Stiles, G., Foster, J. C., and Doupnik, J. R.: Prolonged radar observations of an auroral arc, J. Geophys. Res., 85(A3), 1223-1234, 1980.

Sun, Z.-P., Turco, R. P., Walterscheid, R. L., Venkateswaran, S. V., and Jones, P. W.: Thermospheric response to morningside diffuse aurora: High-resolution three-dimensional simulations, J. Geophys. Res., 100(A12), 23 779-23 794, doi:10.1029/95JA02298, 1995.
Tao, X. and Gardner, C. S.: Heat flux observations in the mesopause region above Haleakala, Geophys. Res. Lett., 22(20), 28292832, 1995.

Thayer, J. P.: Height-resolved Joule heating rates in the highlatitude E region and the influence of neutral winds, J. Geophys. Res., 103(A1), 471-487, 1998.

Thayer, J. P.: High-latitude currents and their energy exchange with the ionosphere-thermosphere system, J. Geophys. Res., 105(A10), 23 015-23 024, 2000.

Vickrey, J. F., Vondrak, R. R., and Matthews, S. J.: Energy deposition by precipitating particles and Joule dissipation in the auroral ionosphere, J. Geophys. Res., 87(A7), 5184-5196, 1982.

Wang, D. Y. and Fritts, D. C.: Mesospheric momentum fluxes observed by the MST radar at Poker Flat, Alaska, J. Atmos. Phys., 47(12), 1512-1521, 1990.

Wedde, T., Doupnik, J. R., and Banks, P. M.: Chatanika observations of the latitudinal structure of electric fields and particle precipitation on November 21, 1975, J. Geophys. Res., 82(19), 2743-2751, 1977.

Woodman, R. F. and Guillen, A.: Radar observations of winds and turbulence in the stratosphere and mesosphere, J. Atmos. Sci., 31, 493-505, 1974.

Zhou, Q. H.: Incoherent scatter radar measurement of vertical winds in the mesosphere, Geophys. Res. Lett., 27(12), 18031806, 2000.

Ziesollek, C., Baumjohann, W., Brüning, K., Carlson, C. W., and Bush, R. I.: Comparison of height-integrated current densities derived from ground-based magnetometer and rocket-borne observations during the Porcupine F3 and F4 flights, J. Geophys. Res., 88(A10), 8063-8072, 1983. 